\title{
Los conglomerados empresariales en el Ecuador: un análisis histórico, económico y político*
}

\author{
Business Groups in Ecuador: a Historical, \\ Economic and Political Analysis
}

\section{Os conglomerados empresariais no ambiente econômico e político do Equador}

Giuseppe Vanoni-Martínez

Carlos Rodríguez-Romero

\footnotetext{
* Este artículo hace parte de la investigación doctoral que se desarrolla para la Universidad del Rosario de Colombia, dentro del grupo de investigación en Dirección y Gerencia en la línea de investigación en Estrategia, cuyo título es: "Estrategias de crecimiento de los conglomerados ecuatorianos: un estudio de cuatro grandes grupos".

** Ph D. (c) de la Universidad del Rosario e investigador del grupo GRIEGO de la Universidad Nacional de Colombia. giuseppe.vanoni@urosario.edu.co (iD http://orcid.org/0000-0002-9884-066X

*** PhD. Director del Grupo GRIEGO y profesor tiempo completo de la Universidad Nacional de Colombia carodriguezro@unal.edu.co (iD http://orcid.org/0000-0001-5007-8293
} 


\section{Resumen}

El objetivo del presente artículo es analizar la influencia histórica que han tenido los conglomerados empresariales en Ecuador, sobre todo durante el período 1965-2000. Aplicando el proceso metodológico de Quivy y Van Campenhoudt se identificaron, en primera instancia, las diferentes aproximaciones teóricas que existen sobre los conglomerados. Posteriormente se dividió el período de estudio en etapas que explican cómo históricamente, agroexportadores, comerciantes, industriales y banqueros se incorporaban por medio de pactos y presiones en el acontecer diario de la economía y política ecuatoriana. Como resultado se puede decir que los conglomerados han tenido una influencia histórica en lo político y económico desde las modalidades de acumulación más básicas como lo fue la hacienda. Se concluye que en Ecuador su presencia ha estado ligada a los diferentes gobiernos de turno, civiles y militares, manejando de forma directa o indirecta los momentos políticos y económicos de mayor incertidumbre para el país.

Palabras clave: conglomerados, concentración de capital, grupos económicos, entorno económico, entorno político, modalidades de acumulación.

Clasificación JEL: L10, M10, M21, N00

\section{Abstract}

This article aims to analyze the historical influence of the business conglomerates on Ecuador, especially during the period 1965 to 2000. Through the Quivy and Van Campenhoudt methodological process were identified the different theoretical approaches of the conglomerates. Then, the period of study was divided into stages that explain in a historical way how agricultural exporters, traders, industrialists and bankers were getting involved trough pacts and pressures into the Ecuadorian economy and politics. As a result, the conglomerates have had a historical influence on the political and economic areas from the most basic modes of accumulation like the estate. In conclusion, the business conglomerates in Ecuador have been linked to the different civilian and military governments handling in a direct or indirect way, the most vulnerable political and economic moments of the country.

Keywords: conglomerates, concentration of capital, business groups, economical environment, political environment, modes of accumulation. 


\section{Resumo}

A meta deste artigo é analisar a influencia histórica dos conglomerados empresariais em Equador, especialmente durante o período 1965-2000. O proceso Quivy e Van Campenhoudt foi aplicado para identificar as diferentes teorias deste conceito, depois, o período de estudo foi dividido em estágios que explicam a incorporação o setor agroexportador e industrial e dos comerciantes e banqueiros na vida económica e política através dos acordos e convênios com a proteção dos diferentes governos. Este trabalho descobriu que os conglomerados terão tido a influencia histórica em áreas económicas e políticas e começou com a forma básica de acumulação como era a fazenda. Para concluir, os conglomerados em Equador terão estado ligados com os diferentes governos e dominaram, de forma direita e indireta os momentos mais difíceis do país.

Palavras chaves: aglomeração, ambiente económico, ambiente político, concentração do capital, grupos económicos, modalidades de acumulação 


\section{INTRODUCCIÓN}

En América Latina, el estudio de los conglomerados empresariales o grupos económicos adquiere importancia a mediados de los años 60 , con investigaciones entre las que se destacan las desarrolladas por Lagos (1965) y Dahse (1979) en Chile; Misas Arango (1975), Silva-Colmeneras (1977), en Colombia; Strachan (1976) en Nicaragua; Navarro (1976) en Ecuador, entre otras. Y, aunque la información de las actividades de los conglomerados no está fácilmente a disposición en los diferentes países, los investigadores han logrado inferir ciertas conclusiones que denotan la importancia de estos en la región. Por ejemplo, Strachan (1976) identificó en Nicaragua la presencia de cuatro grupos económicos que poseían el 35 \% de los préstamos del sector financiero y que ocupaban parte importante del sector privado. Bisang (1999) explica que, para la década de los años 1980, en Argentina, aproximadamente unos cuarenta conglomerados tenían una facturación que alcanzaba el 30 \% del valor bruto total de producción en el país. Mientras que, en Colombia, Silva Colmenares (1977) se refirió a ellos como "los verdaderos dueños del país".

El crecimiento de los conglomerados en América Latina respondió a tres lógicas específicas: 1) la expansión desde una base de recursos naturales; 2) el crecimiento por diversificación que genera sinergias; y 3) el resultado de grupos generados alrededor de organizaciones financieras y vinculadas con otros servicios (Sánchez \& Paredes, 1994; Rodríguez-Satizábal, 2014; Silva-Colmenares \& Padilla, 2015; Vanoni, 2105). Por otra parte, el ambiente proteccionista que primaba hasta inicios de los años ochenta se daba por el modelo de industrialización sustitutiva de las importaciones (ISI), el mismo que en su desarrollo presentó desequilibrios internos y externos, aunque en apariencia, 
la ISI generaba nuevos sectores rentables, lo que llevó a las empresas a implementar -como una forma de crecimientoestrategias de integración vertical, conglomeración y de diversificación de sus inversiones en diferentes sectores. Así se constituyeron conglomerados de gran tamaño que accedían a condiciones de crédito privilegiadas, que diversificaban el riesgo ante la incertidumbre del entorno y que aprovechaban economías de escala.

En Ecuador, los conglomerados empresariales son uno de los principales resultados que dejaron las políticas del modelo ISI. Estas contribuyeron a conformar, a través de una serie de empresas nacionales privadas, estatales y transnacionales, un núcleo de estructura industrial orientado principalmente a los mercados internos. Por lo que el país, igual que otras naciones de América Latina, transitó por múltiples modalidades de acumulación, las que han estado en línea con diversas alianzas realizadas por parte de los grupos dominantes, los cuales han operado dentro de estructuras estatales y configuraciones económicas muy particulares en las diferentes regiones del país y se han valido de sus fortalezas para incorporarse a los mercados internacionales.

Dada la influencia que han tenido los conglomerados en Ecuador, el artículo inicia su análisis en el año 1965 -momento en que el país era gobernado por una junta militar que adoptó el modelo ISI, donde se dieron múltiples situaciones desde la perspectiva económica y política, propiciadas por los conglomerados y que incidieron de manera importante en la nación- y concluye con el inicio de la dolarización en enero del año 2000. Por lo tanto, se intentan responder los siguientes cuestionamientos: ¿Cuáles son los principales cambios que se han presentado en el plano económico-político durante el período 1965-2000? ¿Qué papel han desempeñado los conglomerados sobre el entorno político-económico en Ecuador? ¿Cómo incidieron los conglomerados en las decisiones económicas y políticas en el país?

El trabajo metodológicamente se adhirió a la ruta que sigue la trayectoria de Quivy y Van Campenhoudt (2005), quienes categorizan las investigaciones en tres momentos:

1. Ruptura: es el primer paso en la investigación. Con este se procura romper con los prejuicios y las falsas pruebas. En esta etapa, el investigador plantea su pregunta inicial, despejándose a través de lecturas. Este acto inicial desemboca en la problemática de investigación.

2. Estructuración: esta etapa solo se da cuando la lógica del fenómeno supuesta por el investigador queda más claramente explicada. Si no existe un marco teórico estructurado, no puede existir una comprobación fructífera. Aquí, el investigador asume posturas que le permiten, de forma positivista, constructivista u otra, comprender su objeto de trabajo.

3. Comprobación: esta fase involucra la observación, el análisis de la 
información y las conclusiones finales que el investigador logra generar.

Con fundamento en la metodología se planteó el objetivo, el cual consiste en analizar la influencia política y económica de los conglomerados empresariales en Ecuador, y se encuentra ligado a las etapas descritas. Para conseguirlo se realizó: 1) la búsqueda de información de tipo exploratorio, a fin de encontrar diversas posturas al respecto de la problemática inicial; 2) la lectura y el análisis de fuentes bibliográficas como journals identificados en bases ISI, Scopus, Jstore, recurriendo a operadores boleanos y cadenas de búsqueda y libros sugeridos por expertos en el tema; 3) la construcción del marco conceptual objeto de estudio; 4) la construcción histórica de los sucesos en los que estuvieron presentes los conglomerados; y finalmente se desarrollaron las conclusiones

Para una mejor comprensión del lector, el artículo se estructura en la primera parte con las nociones que diversos autores ofrecen sobre lo que significa un conglomerado y sus puntos de convergencia. En la segunda parte se analiza cada uno de los acontecimientos históricos que los autores identifican como relevantes dentro del desenvolvimiento económico y político del Ecuador y cómo los conglomerados actuaron en dicho entorno. En último término se extraen las conclusiones del período analizado.

\section{NOCIONES ASOCIADAS AL CON- CEPTO DE CONGLOMERADOS}

Varias formas de concentración económica estuvieron presentes a finales del siglo XIX e inicios del XX, pero la que más resalta en el capitalismo moderno por su presencia, proliferación e importancia (Herzog, Munir \& Kattuman, 2013) es la de los conglomerados empresariales, con sus múltiples denominaciones dependiendo del país del que se trate. Por ejemplo, en Alemania se les conoce bajo el nombre de Konzerne; en América Latina, grupos económicos; en China, quiye jituan; en Corea, chaeboles; en Estados Unidos, business groups; en Hong Kong, Hongs; en Italia, grupos económicos; en la India, casas de negocios; en Japón, keiretsus o kigyo shudan; en Rusia, oligarchs; en Taiwán, guanxiqiye; y en Turquía, compañías holding (Carney, Gedajlovic, Heugens, Van Essen \& Van Oosterhout, 2010; Kim, Kandemir \& Cavusgil, 2004).

Por esta multiplicidad de denominaciones es complicado definir de manera exacta un concepto que los identifique. Y aunque estas varíen entre disciplinas, países e investigadores que los estudian, hay tres puntos de convergencia en la formación de los conglomerados (ver Tabla 1). 
Tabla 1. Puntos en los cuales convergen los conglomerados empresariales

\begin{tabular}{|l|l|}
\hline \multicolumn{1}{|c|}{ Puntos de covergencia } & \multicolumn{1}{c|}{ Autor (es) } \\
\hline Presencia de lazos familiares entre directivos. & $\begin{array}{l}\text { Hsieha, Yehb \& Chen (2010), Ghemawat \& Khanna } \\
\text { (1998); Khanna \& Yafeh (2007); Leff (1978); Rodríguez- } \\
\text { Romero \& Duque (2008); Rodríguez-Satizábal (2014). }\end{array}$ \\
\hline Gestión centralizada. & $\begin{array}{l}\text { Cainelli \& Iacobucci (2011) De Montmorillon (1986); } \\
\text { Granovetter (1994); Khanna \& Yafeh (2007); Lagos } \\
\text { (1965); Rodríguez-Romero \& Duque (2008); Rodríguez- } \\
\text { Satizábal (2014); Wilches \& Rodríguez-Romero (2016). }\end{array}$ \\
\hline \multirow{2}{*}{$\begin{array}{l}\text { Vínculos económicos entre empresas que conforman } \\
\text { el conglomerado. }\end{array}$} & $\begin{array}{l}\text { Farías (2014), Ghemawat y Khanna (1998); Khanna } \\
\text { \& Rivkin (2001); Khanna \& Yafeh (2007); Rodríguez- } \\
\text { Romero \& Tovar (2007); Rodríguez-Romero \& Duque } \\
\text { (2007); Wilches \& Rodríguez-Romero (2016); Silva- } \\
\text { Colmenares (1977); Tanriverdi \& Venkatraman (2005); } \\
\text { Whitley (1992). }\end{array}$ \\
\hline
\end{tabular}

Según el trabajo de Chudnovsky y López (1998), realizado en América Latina, los grupos económicos son dirigidos o controlados por determinadas familias, aunque existe una tendencia creciente a incorporar inversores externos, así como métodos de dirección y estructuración organizacional más profesionales. Granovetter (1994) los entiende como empresas independientes operativamente, pero coordinadas de forma centralizada. Además, sus actividades pueden concentrarse en un producto determinado, diversificado por medio de una integración vertical o bien organizarse en grupos que operan en varios sectores, pero sensibles a los contextos económicos y políticos de los países (Bamiatzi, Cavusgil, Jabbour \& Sinkovics, 2014).

Rodríguez-Satizábal (2014), al respecto de lo que es un conglomerado empresarial, indica:

Las estructuras conglomeradas como multiempresas, participan haciendo negocios en diferentes mercados, sea por medio de operaciones de integración vertical o integración horizontal en las fases de su cadena de valor o en las industrias no relacionadas, bajo una administración y control financiero común donde los participantes tienen vínculos de relaciones de confianza (familiares o de amistad), interpersonales. Sobre una base de un común trasfondo personal, étnico o comercial similar (p. 44).

Los conglomerados constituyen, por lo tanto, estructuras que 1) concentran importantes capitales pertenecientes a grupos familiares, y 2) se identifican en el mercado bajo características de sociedades mercantiles, anónimas o limitadas, que sirven como distractores frente a la ley, pues carecen de un mecanismo de participación y democratización de las acciones. El hecho de que se originaron en sectores dominantes y que implementaron diversos procesos de integración vertical 
y horizontal, les permitió lograr un gran desarrollo e influencia sobre lo económico y lo político. De esa manera, los grupos se han diversificado y consolidado de manera exitosa, hasta convertirse en lo que son en la actualidad (Sánchez \& Paredes, 1994).
De manera sintética, la Tabla 2 presenta las investigaciones de algunos de los principales autores que han abordado el fenómeno de los conglomerados e identifica los aspectos más relevantes de los mismos.

Tabla 2. Elementos característicos de la conformación de los conglomerados

\begin{tabular}{|c|c|c|c|c|c|c|c|c|c|c|}
\hline Autor y país & 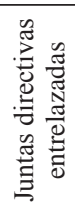 & 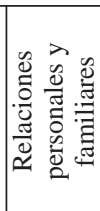 & 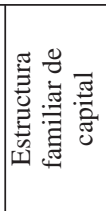 & 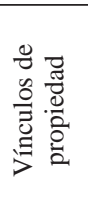 & 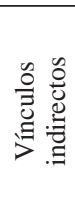 & 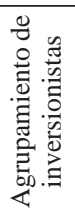 & 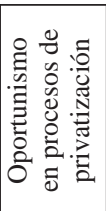 & 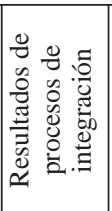 & 苞 & 莺莡 \\
\hline $\begin{array}{c}\text { Chudnovsky \& } \\
\text { López (1998) } \\
\text { (Argentina) }\end{array}$ & & $\mathrm{X}$ & & & & & & & $\mathrm{X}$ & $\mathrm{X}$ \\
\hline $\begin{array}{c}\text { Collin (1998) } \\
\text { (Suecia) }\end{array}$ & & & & $\mathrm{X}$ & & $\mathrm{X}$ & & & $\mathrm{X}$ & $\mathrm{X}$ \\
\hline $\begin{array}{c}\text { Del Villar et al. } \\
\text { (1999) } \\
\text { (Chile) }\end{array}$ & & $\mathrm{X}$ & & $\mathrm{X}$ & & & & & $\mathrm{X}$ & $\mathrm{X}$ \\
\hline $\begin{array}{c}\text { Figuière (1992) } \\
\text { (Japón) }\end{array}$ & $\mathrm{X}$ & & & $X$ & $\mathrm{X}$ & $\mathrm{X}$ & & & $\mathrm{X}$ & $\mathrm{X}$ \\
\hline $\begin{array}{c}\text { Franco \& De } \\
\text { Lombaerde (2000) } \\
\text { (Colombia) }\end{array}$ & & $\mathrm{X}$ & & & & & $\mathrm{X}$ & & $\mathrm{X}$ & $\mathrm{X}$ \\
\hline \begin{tabular}{|c|} 
Garrido \& Peres \\
(1998) \\
(Chile) \\
\end{tabular} & & $\mathrm{X}$ & $\mathrm{X}$ & & & & & & $\mathrm{X}$ & $\mathrm{X}$ \\
\hline $\begin{array}{c}\text { Ghemawat \& } \\
\text { Khana (1998) } \\
\text { (Estados Unidos) }\end{array}$ & & $\mathrm{X}$ & & & & $\mathrm{X}$ & & $\mathrm{X}$ & $\mathrm{X}$ & $\mathrm{X}$ \\
\hline $\begin{array}{c}\text { Granovetter } \\
(1994) \\
\text { (Estados Unidos) }\end{array}$ & & & & $\mathrm{X}$ & & & & $\mathrm{X}$ & $\mathrm{X}$ & $\mathrm{X}$ \\
\hline $\begin{array}{c}\text { Grant (2002) } \\
\text { (Estados Unidos) }\end{array}$ & & & & & $\mathrm{X}$ & $\mathrm{X}$ & & $\mathrm{X}$ & $\mathrm{X}$ & $\mathrm{X}$ \\
\hline $\begin{array}{c}\text { Khanna \& Rinking } \\
(2000) \\
\text { (Estados Unidos) }\end{array}$ & $\mathrm{X}$ & & & $\mathrm{X}$ & $\mathrm{X}$ & & & & $X$ & $\mathrm{X}$ \\
\hline \begin{tabular}{|c|} 
Khanna \& Yafeh \\
(2007) \\
(varios países \\
emergentes)
\end{tabular} & $\mathrm{X}$ & $\mathrm{X}$ & $\mathrm{X}$ & $\mathrm{X}$ & $\mathrm{X}$ & & & & $\mathrm{X}$ & $\mathrm{X}$ \\
\hline $\begin{array}{l}\text { Kim et al. (2003) } \\
\text { (Estados Unidos) }\end{array}$ & & $\mathrm{X}$ & $\mathrm{X}$ & & & & & & $\mathrm{X}$ & $\mathrm{X}$ \\
\hline $\begin{array}{l}\text { Lagos (1965) } \\
\text { (Chile) }\end{array}$ & $\mathrm{X}$ & $\mathrm{X}$ & & & & & & & $\mathrm{X}$ & $\mathrm{X}$ \\
\hline
\end{tabular}




\begin{tabular}{|c|c|c|c|c|c|c|c|c|c|c|}
\hline Autor y país & 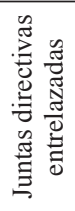 & 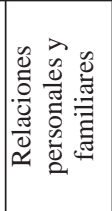 & 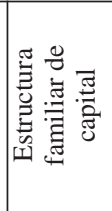 & 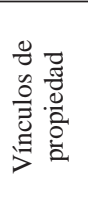 & 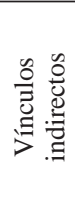 & 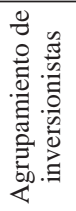 & 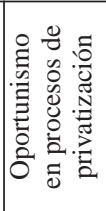 & 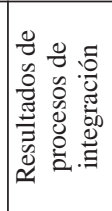 & 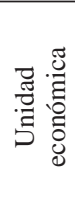 & 语: \\
\hline \begin{tabular}{|l|} 
Lewellen (1971) \\
(Estados Unidos)
\end{tabular} & & & & $\mathrm{X}$ & & $\mathrm{X}$ & & & $\mathrm{X}$ & $\mathrm{X}$ \\
\hline $\begin{array}{c}\text { Leff (1978) } \\
\text { (Estados Unidos) }\end{array}$ & & $\mathrm{X}$ & & & & & & & $\mathrm{X}$ & $\mathrm{X}$ \\
\hline $\begin{array}{c}\text { Maman (2002) } \\
\text { (Israel) }\end{array}$ & $\mathrm{X}$ & & & $\mathrm{X}$ & $\mathrm{X}$ & & & & $\mathrm{X}$ & $\mathrm{X}$ \\
\hline $\begin{array}{l}\text { Montmorillon } \\
\text { (1986) } \\
\text { (Francia) }\end{array}$ & & & & & & $\mathrm{X}$ & & & $\mathrm{X}$ & $\mathrm{X}$ \\
\hline $\begin{array}{l}\text { Nieto (2003) } \\
\text { (Colombia) }\end{array}$ & & $\mathrm{X}$ & $\mathrm{X}$ & & $\mathrm{X}$ & & $\mathrm{X}$ & $\mathrm{X}$ & $\mathrm{X}$ & $\mathrm{X}$ \\
\hline $\begin{array}{c}\text { Pluchart (1999) } \\
\text { (Francia) }\end{array}$ & & $\mathrm{X}$ & $\mathrm{X}$ & & & & & $\mathrm{X}$ & $\mathrm{X}$ & $\mathrm{X}$ \\
\hline $\begin{array}{c}\text { Rettberg (2003) } \\
\text { (Colombia) }\end{array}$ & $\mathrm{X}$ & & $\mathrm{X}$ & & & & & $\mathrm{X}$ & $\mathrm{X}$ & $\mathrm{X}$ \\
\hline \begin{tabular}{|c} 
Rodríguez- \\
Satizábal (2014) \\
(Colombia)
\end{tabular} & & $\mathrm{X}$ & $X$ & $X$ & & & $\mathrm{X}$ & $X$ & $\mathrm{X}$ & $\mathrm{X}$ \\
\hline $\begin{array}{c}\text { Silva-Colmenares } \\
(1977)\end{array}$ & $\mathrm{X}$ & & $X$ & $\mathrm{X}$ & & $\mathrm{X}$ & $\mathrm{X}$ & $\mathrm{X}$ & $\mathrm{X}$ & $\mathrm{X}$ \\
\hline $\begin{array}{c}\text { (Colombia) } \\
\text { Whitley (1992) } \\
\text { (varios países } \\
\text { asiáticos) }\end{array}$ & $\mathrm{X}$ & $\mathrm{X}$ & $\mathrm{X}$ & & & & $\mathrm{X}$ & $\mathrm{X}$ & $\mathrm{X}$ & $\mathrm{X}$ \\
\hline
\end{tabular}

Fuente: Rodríguez-Romero (2011, p. 144). La tabla fue complementada incluyendo los trabajos de Khanna y Yafeh (2007) y Rodríguez-Satizábal (2014).

EL ORIGEN DE LOS CONGLOMERADOS EN ECUADOR

Para comprender de mejor forma lo que acontece en una nación en el presente, siempre es importante mirar su pasado, ya que, posiblemente, muchas de las decisiones que se toman en la actualidad tienen una base histórica. A pesar de lo expresado, establecer con certeza y claridad los momentos exactos en que se llevaron a cabo las diferentes modalidades de acumulación en Ecuador no es sencillo (Bonilla, 1990), aunque las fluctuaciones y los períodos de inestabilidad de la economía local coinciden con las crisis (cíclicas) del capitalismo mundial (Hoffman 1992). Sin embargo, se pueden identificar dos fases de acumulación previas a 1965, aunque superpuestas en el tiempo: 1) fase de rezagos de la modalidad colonial, y 2) modalidad primario-exportadora (Acosta, 2006; Correa, 2009).

Schuldt (1980) explica que la diferencia sustancial entre Ecuador y el resto de países de América Latina es tal vez el 
“rezago del modelo colonial”. Por esta razón es necesario identificar para cada situación, las clases dominantes, los grupos subordinados y los estratos menos favorecidos (marginados) de los sistemas políticos y económicos (Schuldt, 1992).

En relación con lo anterior, Acosta (2006) resalta la importancia de comprender de manera adecuada "el proceso de transición de una modalidad de acumulación a otra, así como la dinámica socio-política [sic] inherente a cada una de ellas, lo cual implica considerar correctamente la compleja mediación entre lo económico, lo social y lo político; es decir, la interacción entre la estructura económica, las clases y el Estado" (p. 17).

\section{Rezagos de la modalidad colonial}

Los grupos propietarios criollos se consolidaron en Ecuador por la modalidad de acumulación, que era el sistema de haciendas que vinculaba a través del mecanismo del concertaje ${ }^{1}$ a la fuerza laboral indígena liberada de los obrajes ${ }^{2}$ (Zambrano, 2011). Posteriormente, ya convertidos en latifundistas (superiores a 10.000 hectáreas), estructuraron su poder económico colonial, al acceder al poder político, el cual les permitió expandirse en los ámbitos financiero y comercial (Ayala, 2008). De acuerdo con Acosta
(2006, p. 21), “estas oligarquías criollas emplearon mecanismos coloniales para garantizar y sacralizar su dominio", lo que Quijano (2001, p. 92) denomina "la colonialidad del poder". Así, el predominio de la colonialidad permanece como el causante de una debilidad estructural (González, 1970). Esto explica que la suerte de los dominados solo es motivo de preocupación por parte de los dominantes cuando los intereses de estos últimos se ven en riesgo (Peralta, 1983).

Con la mencionada debilidad, una alianza sociopolítica conformada por los tenedores civiles de grandes extensiones de tierra, los exportadores e importadores, el militarismo grancolombiano (aún presente durante el primer lustro posterior a la independencia, 1830-1835) y la Iglesia católica (Hurtado, 1977), configuró en su beneficio lo heredado de la colonia. Esta agrupación de poderes promovió un proyecto nacional terrateniente, con el fin de cohesionar, desde el ente central, a toda la sociedad, y someter a ciertos poderes -como la Iglesia y los militares- a la dirección del Estado (Vega, 1991, p. 18). El mencionado proyecto no se afianzó por la anarquía y los despotismos ${ }^{3}$ existentes y porque los intereses reinantes de sectores dominantes de la Costa ${ }^{4}$ y de la Sierra $^{5}$ no modificaron sus sistemas de dominios y de servidumbre (Maiguashca,

$1 \quad$ Un contrato que obligaba a un indígena a realizar tareas agrícolas de modo vitalicio y hereditario, sin salario o con un salario mínimo.

2 En la América colonial y especialmente en la Nueva España, estas eran pequeñas industrias que existieron desde mediados del siglo XVI hasta el siglo XIX, donde, en su mayoría, los indígenas fabricaban productos textiles.

3 Gobiernos absolutos no limitados por leyes que abusan de la superioridad o fuerza que tienen.

4 Representada por cacaoteros de la ciudad de Guayaquil.

5 Básicamente dominada por terratenientes de la ciudad de Quito. 
1992). En cambio, se produjo una forma de servicio por parte del Estado a los intereses de las mencionadas alianzas de poder, la cual excluía de los beneficios a las masas indígenas y a los mestizos, por no existir un hilo histórico que los uniera.

Otras formas coloniales de acumulación y, a la vez, de explotación, fueron "las precarias”, la cuales se mantuvieron hasta la mitad del siglo XX, representadas por los huasipungueros ${ }^{6}$, los yanaperos ${ }^{7}$, los arrendatarios ${ }^{8}$, los aparceros ${ }^{9}$ y las huasicamas ${ }^{10}$. Estas eran características en la Sierra ecuatoriana, mientras que en la Costa se presentaban la gran propiedad y la concentración de tierras en pocas familias ${ }^{11}$, las cuales normalmente estaban ligadas a actividades agroexportadoras vinculadas con productos como el cacao (Chiriboga, 1980, pp. 176-178). Ellas ampliaban sus superficies de siembra y se apropiaban, en virtud de su expansionismo, de las tierras de otros campesinos (Guerrero, 1980, pp. 44-48).

Paralelamente, los hacendados, que también eran exportadores de cacao, banqueros y comerciantes, establecieron relaciones que les permitían mantener una existencia mutua. Esto fue el inicio de grupos financieros que han definido la vida económica y sociopolítica de Ecuador (Guerrero, 1980, p. 82-83). Sin embargo, como resultado de la explotación étnica y de sus necesidades personales de acumulación, estos propiciaron una modalidad de exportaciones basada en productos primarios (primaria exportadora).

\section{Modalidad primario exportadora (1860)}

En este primer período de vida económica republicana se consolidaron las bases de una modalidad de acumulación propiciada por la escasa diversificación y la dependencia de un número reducido de productos agropecuarios como el cacao y posteriormente el banano. Este hecho ubicó al Ecuador en el mercado mundial como un país de modalidad agroexportadora primaria (Uquillas, 2008). Aunque, a diferencia de otras experiencias latinoamericanas, la inserción internacional del país fue tardía, inestable, discontinua y con una limitada sustentabilidad ecológica (Fierro, 1991, p. 57)

\footnotetext{
$\overline{6} \quad$ Terrateniente que manejaba sus haciendas con despotismo, haciendo caso omiso de las leyes y vulnerando los derechos de sus esclavos.

7 Campesinos adscritos a la hacienda, los cuales eran obligados a realizar trabajos sin paga, solo a tener pastizales, agua, leña y derecho al tránsito por el territorio.

$8 \quad$ En la colonia, eran los trabajadores que arrendaban pedazos de tierra de los terratenientes. Estos debían encargarse de lo relacionado con el cultivo de la misma y debían pagar por ella, incluso con trabajo, en la hacienda que los acogía.

$9 \quad$ Contrato por el cual el propietario de una finca rústica (cedente aparcero) encarga a una persona física (cesionario aparcero) la explotación agrícola de la misma a cambio de un porcentaje en los resultados.

10 Quienes se encargan de las labores sucias y duras en un hogar. En la serranía ecuatoriana se les conoce como sirvientes.

11 Aspiazu, Seminario, Puga, Cerro, Morla, Parodi, Madinyá y Rosales, entre otras, eran los apellidos de las familias terratenientes de la época.
} 


\section{Auge cacaotero}

Con mayor fortaleza, a inicios de 1860 y a consecuencia de condiciones naturales favorables, se propició un auge del cacao, con el $70 \%$ de las exportaciones del país correspondientes a ese cultivo. Las plantaciones se concentraron en treinta familias costeñas que aglutinaban la producción (Larrea, 2005). Así, banqueros, comerciantes y productores, unidos por las exportaciones de la fruta, eran quienes lideraban los cambios económicos del país. Pese a que las exportaciones insertaban a Ecuador en los mercados internacionales, no existía una vinculación dinámica entre la producción cacaotera y el resto de la economía. Por lo que los excedentes generados se desviaron a países industrializados, se pagaron regalías para las inversiones extranjeras y, adicionalmente, se dio una fuga de capitales y pagos de utilidades de deuda y de importaciones de bienes suntuosos (Correa, 2009).

De esa forma, se minimizó la reproducción del capital local, y esto, junto con los problemas cacaoteros iniciados en 1920, pero continuados años después (en 1930 las exportaciones descendieron un $29 \%$ ), produjo la crisis de mayor inestabilidad política y económica del país. La pobreza fue el resultado inmediato de esta situación. La miseria, de hecho, generó la movilización de las masas con el fin de reclamar sus derechos y aspiraciones.
Como resultado, los grupos de poder, tanto de la Costa como de la Sierra, se debilitaron (Acosta, 2006).

\section{Auge bananero}

A finales de la década del 40 comenzó un período conocido como la época de estabilidad bananera. En esa etapa, Galo Plaza Lasso ${ }^{12}$, apoyado por el partido político Movimiento Cívico Democrático, ganó las elecciones presidenciales (1948-1952), lo que permitió articular los intereses económicos y políticos de latifundistas, agroexportadores, comerciales e industriales del país (Comisión Económica para América Latina y el Caribe [CEPAL], 2013). La bonanza se reflejaba en la producción y exportación de una nueva fruta, cuyo cultivo se estimaba en 30.530 hectáreas, lo que no solo dio a la economía una oportunidad de expandirse, sino que con este cultivo el país se introdujo en las relaciones capitalistas, por lo que dicha etapa formó parte del período que Uquillas $(2008$, p. 2) denominó "desarrollista" (dado entre 1950 y 1980).

La concentración de tierras en pocas familias disminuyó, debido a que aquellas dedicadas al cultivo del banano pertenecían a colonos de estratos medios urbanos. Lo que amplió la frontera agrícola de la Costa, generando 3.000 propiedades, entre pequeñas y medianas bananeras, con extensiones promedio de

\footnotetext{
12 Nacido en Nueva York, heredero de dos de las familias más opulentas del país y propietario de grandes latifundios en la provincia de Imbabura y Cotopaxi.
} 
entre 50 (CEPAL, 2013) y 64 hectáreas (Uquillas, 2008). Aunque fueron múltiples los avances del modelo, la dependencia de la exportación de materias primas y de la importación de bienes de capital se incrementaba, mientras se fortalecía el dominio de las grandes agrícolas transnacionales, que manejaban el 80 $\%$ de las exportaciones (con superficies de cultivos que podían sobrepasar las 1.000 hectáreas tecnificadas). Solo entre Standard Fruit Co. y Bananera Noboa concentraban el $50 \%$ de las exportaciones y recibían prebendas del Estado por la comercialización y exportación. Esta última, fundada por el empresario Luis Noboa Naranjo, se consolidaba en las exportaciones gracias a su propia flota de barcos.

Este escenario generó conflictos de trabajadores, movimientos campesinos y productores contra las exportadoras. Sin embargo, de acuerdo con Acosta (2006, p. 102), "no implicó una pérdida de hegemonía de la burguesía agroexportadora que siguió demostrando agilidad y capacidad de acción para aprovechar las cambiantes coyunturas, así como para influir de forma directa o indirecta sobre el manejo de la cosa pública”.

A finales de la década del 50, debido a problemas en el mercado internacional y la aparición del "Mal de Panamá" en las bananeras locales, las exportaciones de la fruta comenzaron a declinar, llegando a su nivel más crítico en 1964, lo que generó una balanza comercial deficitaria, mientras el modelo agroexportador se agotaba en sus estructuras tradicionales de funcionamiento.

\section{ENTORNO ECONÓMICO Y POLÍ- TICO DEL ECUADOR: 1965-2000}

El peso político del Estado fue primordial para gestar otro tipo de modalidad de acumulación, al igual que para controlar los precios relativos básicos de la economía y beneficiar a los grupos empresariales industriales y los manufactureros ligados a los exportadores. Entre ellos supieron acomodarse para, incluso, diversificar sus intereses al sector financiero, sin descuidar sus actividades comerciales, asegurando su estatus con inversiones agrícolas, lo cual, aproximadamente entre 1955 y 1964, los hacía surgir como una alianza empresarial dominante en el Ecuador (Acosta, 2006).

Con la finalidad de comprender mejor el período de análisis (1965-2000), la Figura 1 explica la secuencia de acontecimientos que, a decir de los autores, son las más relevantes para analizar el entorno económico y político sobre los cuales los conglomerados empresariales ejercían de forma directa o indirecta sus mecanismos de presión. 


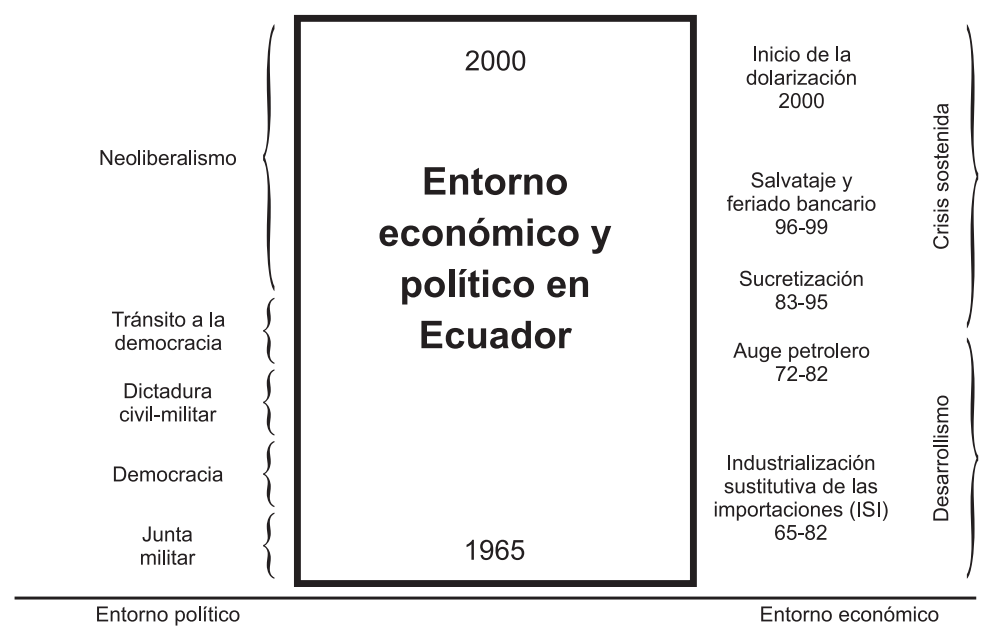

Figura 1. Fenómenos destacados sobre los cuales tuvieron influencia los conglomerados. Fuente: Vanoni (2015).

Industrialización sustitutiva de las importaciones y junta militar

La crisis bananera precipitó el descalabro constitucional, por lo que entre 1963 y 1966 asume las responsabilidades del país una junta militar liderada por el contraalmirante Ramón Castro Jijón, “como vanguardia de la burguesía industrial" (Velasco, 1981, p. 208), quien implementó en su mandato la tónica norteamericana anticomunista e incorporó el modelo de industrialización sustitutiva de las importaciones (ISI). Más aun, cuando previamente el informe de la CEPAL dado en 1953 no era positivo. "El desarrollo económico en el Ecuador es similar al de una economía primitiva, precaria, con una base institucional exigua, que impide la concepción y aplicación de una política de desarrollo" (Uquillas, 2008, pp. 26). El objetivo de los militares que tenían el poder, a decir de ellos, era el de trabajar en pro de una nación y no de unas cuantas familias que tenían la hegemonía en la época tanto en lo productivo como en la acumulación de tierras de todo tipo ${ }^{13}$ (Acosta, 2006).

El modelo ISI pretendía impulsar la economía con la industrialización vía sustitución de importaciones, favoreciendo a este sector en: 1) la elaboración de artículos domésticos, en lugar de importarlos; 2) la ampliación del mercado interno vía creación de sujetos demandantes de esos productos; 3) el crecimiento y la modernización del

$\overline{13}$ Muchos terratenientes de la época tenían territorios improductivos, incluso en los páramos ecuatorianos. 
Estado como reorganizador de la sociedad con legislaciones sociales y laborales que eliminen los desequilibrios que genere el modelo (Acosta, 2006).

Además de estas decisiones, se expidió la Ley de Reforma Agraria, que pretendía cambiar las relaciones precapitalistas e intentaba conseguir objetivos económicos de modernización agrícola y que, aunque en 1964 desapareció al huasipungo, no estaba encuadrada en un verdadero proceso de redistribución productiva nacional, sino más bien, en el capital de los hacendados que querían concentrarse en actividades más lucrativas como el comercio, la construcción y la industria. Por otra parte, durante este mismo período se fomentó el crecimiento de un aparato tecnoburocrático derechista. Estas dos situaciones mencionadas quizás son los principales acontecimientos de un gobierno militar que cuando intentó ser reformista, incorporando impuestos al comercio exterior y reformas tributarias para aumentar recursos para el Estado, sus acciones fueron limitadas por los grupos hegemónicos conformados por banqueros, exportadores y comerciantes, que orquestaban levantamientos sociales que alteraban el andamiaje político de los militares.

En este contexto, la ISI aplicada, que estimulaba la industrialización nacional, no tuvo los efectos esperados. Algunos inconvenientes como: 1) ahorro nacional insuficiente que no permitía financiar el desarrollo, lo que obligaba a buscar inversión y ahorros extranjeros; 2) expansión desmedida del sector público, creciendo en obras de alcance nacional, pero sin un programa claro, planificado y estructurado que brindara beneficios socioeconómicos, lo que propició un deterioro financiero de este sector, arrojando déficits fiscales graves; y 3) desequilibrios intersectoriales (ya que la industrialización del petróleo dejaba rezagado al sector agrícola, con mayor fuerza a partir de 1972), lo que obligaba necesariamente a acudir a grandes cantidades de divisas para financiar la importación de productos de primera necesidad subsidiados por el Gobierno y que servían para la canasta básica (Uquillas, 2008).

Sumado a esto, los conglomerados empresariales no crearon las condiciones adecuadas para que el modelo ISI cristalizara, ni se alteró el patrón de acumulación primario-exportador. Según Acosta (2006):

Fue un esfuerzo asociado y subordinado a la lógica del capital externo lo cual orientó la producción a las satisfacciones de necesidades de grupos minoritarios de la población, fortaleciendo la producción de bienes de consumo para satisfacer esas demandas por sobre la de productos intermedios y de bienes de capital (pp.115-116).

Con dichos acontecimientos, las élites empresariales tanto de la Costa como de la Sierra, enemistadas con el gobierno militar, sabotearon la estabilidad política 
y económica del país ideándose un período presidencial de interinazgo encabezado por Clemente Yerovi Indaburu (marzo a noviembre de 1966), el cual se estableció hasta que los grupos de la época, conformados por exportadores, banqueros y comerciantes, ejerciendo sus influencias económicas y políticas decidieran elegir como presidente interino a Otto Arosemena Gómez (1966-1968).

\section{Auge petrolero y dictadura civil militar}

Durante la década del 70, el Ecuador estuvo a cargo de gobiernos dictatoriales, incluida la dictadura civil de Velasco Ibarra (1968-1972), quien en febrero de 1972 fue destituido por el Gobierno Nacionalista y Revolucionario de las Fuerzas Armadas presidido por el general Guillermo Rodríguez ${ }^{14}$ Lara, quien estableció una estrategia de gobierno enfocada en tres aspectos: 1) la creación de una política aplicada al sector de los hidrocarburos; 2) una política de reforma agraria (la segunda) junto con el programa nacional de colonización; y 3 ) una política modernizadora del Estado y de la economía (Bocco, 1987). Todo esto en medio de una crisis hegemónica con los grupos de poder nacionales que representaban a las transnacionales petroleras.

El auge del petróleo, producto que ha sido, indudablemente, de la mayor importancia para el país en el aspecto económico (más que el cacao y el banano), surge una vez más por las necesidades externas de las multinacionales de buscar nuevas fuentes de aprovisionamiento y no solo por razones nacionales. Aunque su explotación fue un revitalizador para la economía nacional, cuando sus exportaciones pasaron de 190 millones de dólares en 1970 a 2500 millones de dólares en 1981. Esto puso a Ecuador en la lógica del capitalismo, volviéndose más atractivo para la banca internacional, que otorgaba préstamos, al igual que recibía recursos financieros del mercado internacional, que no podía colocar en países industrializados que se encontraban en recesión, pero que podía destinar al país por las necesidades de acumulación de capital (Correa, 2009).

Durante el tiempo que duró el auge del petróleo y por primera vez, el Estado fue el actor principal del desarrollo del país, pero sin olvidarse de beneficiar al empresariado privado, tal como lo expresó el Banco Mundial al mencionar que se garantizaba una serie de subsidios implícitos y poco transparentes (Acosta, 2006, p. 131). Lo que se demuestra con la participación del Estado en proyectos privados poco rentables a corto plazo o en su intervención deliberada de apoyo al proceso de acumulación de los conglomerados empresariales presentes en las década del 70, haciendo presencia en empresas del sector de la aviación, en bancos, ingenios azucareros, empresas de lácteos, semillas, línea blanca, fertilizantes y agropecuarias.

$\overline{14}$ Destituido más tarde, en 1976, por el Consejo Supremo de Gobierno al mando del Almirante Alfredo Poveda Burbano. 
La ayuda estatal a los grupos empresariales privados también incluía mecanismos de subsidios vía congelamientos de precios en las tarifas de las empresas estatales (energía transporte, alimentación), así como políticas de exenciones tributarias y exoneraciones arancelarias, que permitían que se importaran bienes de capital y se establecieran industrias, acciones que también beneficiaron a las medianas empresas. Aunque los conglomerados no manejaban directamente los recursos producidos por el petróleo, sí participaban de los beneficios de la expansión de gasto, de créditos preferenciales para la industria y de la protección que daba la ISI ante la competencia externa.

Además de todos los beneficios mencionados, el Estado también asumió tareas en beneficio de los grupos monopólicos y oligopólicos, otorgando ayudas incluso posteriores a la bonanza petrolera, mientras los ajustes gubernamentales minimizaban las acciones productivas de las pequeñas y medianas empresas.

Pero, a partir de 1982, debido a la caída del precio del petróleo y a la escasez de préstamos a países del tercer mundo, concluyó la bonanza petrolera y quedaron los problemas económicos, que ya un año antes habían aparecido en Ecuador y que se agudizaron con el conflicto fronterizo con el Perú.

\section{Sucretización y tránsito a la democracia}

Debido a la caída de los precios y a la baja de ingresos petroleros, por las restricciones a los mercados de capitales como consecuencia de las políticas monetarias impuestas por los países más industrializados, así como por el incremento de tasas de interés, la deuda externa pública se incrementó. Bajo estas circunstancias, los ajustes por parte del Gobierno afectaron la economía, aunque para los empresarios y para los grupos financieros, el Estado fue la salvación al pago de las deudas privadas contraídas libremente en dólares en el exterior.

Fue durante el Gobierno de transición a la democracia del presidente Dr. Osvaldo Hurtado Larrea ${ }^{15}$ (1981-1984) que se dispuso que las deudas por 1.371 millones de dólares americanos (con fecha septiembre de 1983), contraídas libremente con la banca internacional por algunos agentes económicos privados se transformen en deudas en sucres ${ }^{16}$ pagables al Banco Central del Ecuador, las que correspondían a 40.000 operaciones de 15.000 clientes (Comisión Integral de Auditoria de Crédito Público [CAIC], 2008). Estas decisiones gubernamentales significaban la conversión de deuda privada en deuda pública, situación que Acosta (2008, p. 1) denominó un "proceso de socialización o estatización

$\overline{15}$ Quien era vicepresidente y, con la muerte del presidente Jaime Roldós Aguilera el 24 de mayo de 1981, asume el cargo.

16 Antigua moneda del Ecuador hasta la instauración del dólar americano (enero de 2000) como moneda de circulación diaria y uso transaccional. 
de deudas privadas" y Correa (2009, p. 69) llamó "créditos de estabilización" o simplemente sucretización.

Para que esta medida se pusiera en marcha existieron presiones desde el interior del país por parte de los grupos empresariales que tenían distribuidas sus deudas por sectores y en diferentes porcentajes (industria 31,7 \%; comercio $18,9 \%$; deudas personales $15,7 \%$; construcción $14,3 \%$; financiero $7,4 \%$; servicios 6,2 \%; agricultura 1,7 \%; otros $4.1 \%$ ) (CAIC, 2008). Los otros grupos que internamente presionaban eran los del poder político que no respaldaban al presidente Hurtado. Mientras que externamente, organismos como el Fondo Monetario Internacional (FMI) y el Banco Mundial (BM) argumentaban que el mejor garante de los créditos privados era el Estado (Correa, 2009). Por lo que en el Registro Oficial n. ${ }^{\circ} 585$ del 23 de septiembre de 1983 se publicó el Decreto Ejecutivo 2085, que autorizaba a suscribir los diferentes convenios. Entre estos el artículo 1 literal C establecía:

los mecanismos de depósito y préstamo a celebrarse entre el Banco Central del Ecuador como deudor, el Estado ecuatoriano como garante y cada uno de los acreedores del exterior de créditos adeudados o garantizados por los bancos e instituciones financieras ecuatorianas; convenios que tienen por objeto refinanciar, bajo el mecanismo y condiciones previstas en las Regulaciones $\mathrm{N}^{\circ}$. 101-83 y 113-83, expedidas por la Junta Monetaria el 20 de junio y 26 de julio de 1983, respectivamente, la deuda externa contraída por el sector privado ecuatoriano y registrada en el Banco Central del Ecuador. (CAIC, 2008, p.19)

El discurso gubernamental explicaba que la decisión se tomó como una medida que evitara la debacle económica del Ecuador (ver Tabla 3). De tal forma que la deuda privada se convirtió en una deuda de toda la sociedad ecuatoriana, cuyo plazo de pago fue extendido en el Gobierno de León Febres Cordero (1984-1988). Es decir, que aquellos conglomerados empresariales beneficiados con la sucretización, al igual que personas naturales y jurídicas, volvieron a ser favorecidos. Las nuevas condiciones tenían las siguientes características: 1) el periodo de gracia de 18 meses pasó a cuatro años y medio; 2) los plazos de pago se ampliaron de 3 a 7 años; 3) se congeló la tasa de interés del $16 \%$ cuando las tasas vigentes superaban el $28 \%$; y 4) se anuló la comisión de riesgo cambiario congelando el tipo de cambio en sucres S/. 100 por cada dólar. (Acosta, 2008, p. 5; Correa, 2009, pp. 68-71). 
Tabla 3. Justifcaciones para la sucretización

\begin{tabular}{|c|l|}
\hline ENTORNO & \multicolumn{1}{|c|}{ RAZONES PARA SUCRETIZAR } \\
\hline Productivo & Salvar aparato productivo \\
Empresarial & Impedir quiebra de empresas endeudadas externamente \\
Laboral & Proteger empleo \\
Bancario & Evitar colapso de los bancos \\
Financiero & Estabilizar sistema financiero \\
Cambiario & Mejorar el sistema de libre cambio \\
\hline
\end{tabular}

Lo mencionado demuestra que los más grandes benefactores y los mejores garantes de los intereses empresariales privados fueron los propios gobernantes del Ecuador. Ellos, con sus decisiones, características de gobiernos neoliberales (Merchand, 2012), favorecieron a bancos (el $70 \%$ de los beneficiados quebraron poco tiempo después), equipos de futbol pertenecientes a empresarios transnacionales de la época; clubes sociales (de tenis, golf, automovilismo, ecuestres), que pertenecían y adonde acudían los líderes de los conglomerados empresariales de la época, quienes también como personas naturales se vieron auxiliados por la sucretización. Paradójicamente, en ese mismo grupo de sucretizados aparecen como beneficiados personas del diario acontecer político, económico y gubernamental aún vigentes.

\section{Salvataje y feriado bancario en el neoli- beralismo}

Para finales de la década de los 90, el Ecuador vivió una crisis financiera y fiscal, una inflación acentuada y una recesión de la economía, siendo causas internas y externas las que influyeron para generar dichas condiciones (Figura 2).

$$
\begin{aligned}
& \text { Causas internas }\left\{\begin{array}{cl}
\text { Inestabilidad política } & \{\text { Presidencia sin de apoyo de parte del congreso } \\
\text { Fenómeno de El Niño } & \left\{\begin{array}{l}
\text { Afectó altas zonas de siembras: banado, arroz, camarón, } \\
\text { cacao, pastos }
\end{array}\right. \\
\begin{array}{c}
\text { Guerra con el Perú } \\
(1995)
\end{array} & \left\{\begin{array}{l}
\text { Desviación de recursos para afrontar guerra } \\
(360 \text { millones })
\end{array}\right.
\end{array}\right. \\
& \text { Causas externas }\left\{\begin{array}{l}
\text { Crisis internacional }\{\text { Crisis de países de México, Asia y Rusia } \\
\text { Caída de barril de petróleo a } \$ 7,5\left\{\begin{array}{l}
\text { Elevación del precio de la gasolina } \\
\text { en Ecuador }
\end{array}\right. \\
\text { Suspensión de crédito a países emergente }\{\text { Sin ventajas de renegociación de deuda }
\end{array}\right.
\end{aligned}
$$

Figura 2. Causas internas y externas de inestabilidad en Ecuador. 
Sin embargo, para Espinosa (2000), el origen de la situación económica del país surgió por el comportamiento del sector financiero, ante el marco legal que el presidente Sixto Durán Ballén (1992-1996) introdujo, al extender los límites de los préstamos vinculados ${ }^{17}$ y de la pasividad de su Gobierno (al que se le atribuye ser promotor del neoliberalismo en Ecuador) ante esta forma de actuar de los bancos. La Ley General de Instituciones del Sistema Financiero (LGSIF $\left.{ }^{18}, 1994\right)$, como se denominó, incluía varios tipos de instituciones financieras, entre otras: 1) instituciones financieras privadas, en las que se encontraban los bancos, sociedades financieras, asociaciones mutualistas de ahorro-crédito y crédito para vivienda, cooperativas de ahorro y crédito que realizan intermediación financiera con el público; 2) instituciones de servicios financieros, tales como almacenes generales de depósito, compañías de arrendamiento mercantil, compañías emisoras o administradoras de tarjetas de crédito, casas de cambio, corporaciones de garantía y retrogarantía; y 3) instituciones de servicios auxiliares del sistema financiero, que incluían el transporte de especies monetarias y de valores, servicios de cobranza, cajeros automáticos, servicios contables, servicios de computación, de fomento de las exportaciones, inmobiliarias propietarias de bienes destinados exclusivamente a uso de oficinas de sociedad controladora o institución financiera (Registro Oficial n. ${ }^{\circ} 475$ de 04-jul-1994).

Dicha Ley fue redactada por el vicepresidente de la República, Alberto Dahik, y Ana Lucía Armijos, presidenta de la Junta Bancaria. Para Espinoza (2000), en esta norma se definía de forma difusa lo que era un grupo financiero ${ }^{19} \mathrm{y}$ limitaba el control de estos por parte de la Superintendencia de Bancos, lo que permitió a los banqueros dedicarse a cualquier clase de negocio, en cualquier mercado y en actividades que guardaban relación con procesos de intermediación. Así, se daba inicio a un "concepto de multi-banca, es decir, todas las actividades podían efectuarse en una misma institución o grupo financiero compuesto

$17 \quad$ Préstamos concedidos a grupos económicos que pertenecían a los accionistas de los bancos.

18 Ley $n .^{\circ} 52$, aprobada por el Congreso Nacional el 12 de mayo de 1994, sustituyó a la Ley General de Bancos en vigencia desde 1972 y fue publicada en Registro Oficial 439.

19 A efectos de lo contemplado en la Ley, se entenderá por grupo financiero al integrado por:

a) Una sociedad controladora que posea un banco o una sociedad financiera privada, una compañía de seguros y reaseguros, sociedades de servicios financieros o auxiliares previstas en la Ley, las instituciones previstas en la Ley de Mercado de Valores, así como las subsidiarias del país o del exterior de cualesquiera de las mencionadas) Un banco o sociedad financiera que posea una compañía de seguros y reaseguros, sociedades de servicios financieros o auxiliares previstas en esta Ley, las instituciones previstas en la Ley de Mercado de Valores, así como las subsidiarias del país o del exterior de cualesquiera de éstas.

Salvo lo previsto en el artículo 147 de la Ley, un grupo financiero, cualquiera que sea su conformación, no podrá estar integrado por más de un banco, ni por un banco y una sociedad financiera, ni por más de una compañía de seguros o reaseguros, ni por más de una sociedad financiera al mismo tiempo, ni poseer más de una sociedad de servicios financieros o auxiliares dedicada a la misma actividad. Se entenderá conformado un grupo financiero desde el momento en el que la sociedad controladora, el banco o la sociedad financiera posean una o más de las instituciones señaladas en las letras que anteceden. 
por varias compañías" (Herrera, 2012, p. 24). Estas circunstancias llevaron a la concentración de una mayor cantidad de recursos que guardaban relación directa o indirecta con personas o empresas del mismo conglomerado empresarial.

La nueva ley presentaba dos innovaciones que particularmente permiten comprender cómo crecieron y se fortalecieron los conglomerados en este período: 1) apertura del mercado financiero de todas las instituciones, lo que facilitaba conformar grupos financieros entre las participantes del sistema y con el permiso de la Superintendencia para intervenir en otras compañías; y 2) concedía a los grupos, no a los bancos, la participación en el capital de empresas del sector productivo.

En menos de dos años de dicha liberalización que brindaba la Ley Financiera, el primer banco en presentar problemas fue el Banco Continental, considerado como uno de los más grandes del país. A mediados de 1996 tuvo ya su primera intervención estatal (El Universo, 2007), pues el mercado financiero se desregularizó de tal forma que los créditos vinculados se facilitaron y al banco, que tenía mucha acumulación de este tipo de créditos, se le dificultó la recuperación de su cartera.

En el Gobierno del presidente Jamil Mahuad (1998-2000) los índices de inflación subieron al $60 \%$, el PIB descendió a $-7.3 \%$, la demanda interna disminuyó sobre el $10 \%$, dando como resultado un desempleo del $16 \%$ y un subempleo del $57 \%$, el salario mínimo vital era menor a USD 53, junto a indicadores macroeconómicos que arrojaban un déficit fiscal del $-5.8 \%$, con un pago de deuda externa que se incrementó junto con la amortización del $7 \%$ al $11 \%$ del PIB (Herrera, 2012). Esto propiciaba un efecto parálisis del aparato productivo y recesión de la economía, mientras se acumulaban obligaciones vencidas por parte del sector financiero que aumentaron de 1998 a 1999 del 9.3 $\%$ al $48.5 \%$ respectivamente (Espinosa, 2000).

Y, aunque la banca tomó medidas, aumentando el pago de intereses que estimulaban captaciones de fondos (los cuentacorrentistas preferían sacar su dinero, cambiándolo a dólares), las mismas no dieron resultado. Además se inició un manejo arbitrario por parte de la banca privada, de depósitos del sector público no financiero que se concentraban en las principales instituciones bancarias del país (Herrera, 2012).

La iliquidez ${ }^{20}$ que se generó llevó a la banca privada a solicitar créditos de liquidez de forma frecuente al Banco Central. Para 1998, Filanbanco, considerado como el banco más importante del país, presentó no solo problemas de iliquidez, sino también de solvencia, y por esta razón el presidente Jamil Mahuad le otorgaría 540

$\overline{20} \quad$ Para 1999 habían salido del país 891 millones de dólares. 
millones de dólares, que se transformaron en 800 millones de dólares, del Estado ecuatoriano $^{21}$, para evitar una quiebra sistemática de la institución (días después de que entrara en crisis, el conglomerado dueño del banco inauguró la Cervecería Suramericana, que comercializaría la marca Biela). Jugada a la que luego se denominaría "salvataje bancario" (Acosta, 2006, Correa, 2009; Espinosa, 2000). A esta entrega de dinero hay que agregarle 40 millones de dólares que, por los mismos problemas, también se prestaron al Banco Tungurahua del grupo Finver, al Banco de Préstamos del grupo Peñafiel y Finagro (Espinosa, 2000; Herrera, 2012).

El tercer banco más importante en caer, luego de que algunos pequeños habían sucumbido, fue el de El Progreso, que amparado por la Ley, había concentrado en un reducido número de empresas de su propio conglomerado empresarial créditos vinculados en un $65 \%$. Entre otras instituciones con proporciones del 299 \% a su patrimonio técnico estaba el Banco del Litoral, del grupo Noboa; Rumiñahui del grupo Pichincha -en el que también existían intereses del Ejército ecuatoriano- con $161 \%$; Banco de Guayaquil con $72 \%$; Produbanco con $58 \%$; $49 \%$ para el Banco del Pacífico del grupo financiero Pacífico; con $38 \%$ el Banco del Austro, hoy perteneciente solo al grupo Eljuri; Pichincha del grupo Pichincha; Popular y Previsora con 35 \% (Análisis Semanal, citado por Espinosa, 2000). Cabe aclarar que la ley, hasta esa fecha, permitía que el porcentaje de créditos vinculados, que era del $30 \%$, no podía exceder del $50 \%$ del patrimonio técnico ${ }^{22}$.

ElGobierno,paraminimizarlaincertidumbre generada por la crisis de El Progreso, que tenía 800.000 depositantes, realizó varias corridas de depósitos. Sin embargo, en pocos días estaba en situación de cierre. Por lo que, para evitar el pánico generalizado, el presidente Mahuad intervino el banco, decretando el 1 de marzo de 1999 un feriado bancario de un día, que se extendió a 5, y que como resultado final congeló por un año los depósitos e inversiones a plazo de todos los cuentacorrentistas de los bancos del Ecuador.

\section{Inicio de la dolarización (2000)}

Específicamente, entre los años 1998 y 1999 fueron tres los factores que, según Correa (2009), propiciaron el deterioro económico y la crisis del país: 1) inundaciones provocadas por el fenómeno de El Niño en 1998; 2) la caída de los precios del petróleo entre 1998 y 1999; y 3) la crisis asiática (1997), que generó desconfianza en mercados emergentes, cerró los créditos para América Latina

\footnotetext{
21 Por las fluctuaciones cambiarias.

22 Para la Superintendencia de Bancos del Ecuador, el patrimonio técnico está constituido por la suma de capital pagado, las reservas, el total de las utilidades del ejercicio corriente, las utilidades de ejercicios anteriores, los aportes a futuras capitalizaciones, las obligaciones convertibles, menos la deficiencia de provisiones, amortizaciones y depreciaciones requeridas, desmedros y otras partidas que la institución financiera no haya reconocido como pérdidas y que la Superintendencia de Bancos las catalogue como tales.
} 
junto y causó la quiebra de la banca ecuatoriana entre 1999 y 2001.

Sin embargo, el fenómeno de El Niño no tuvo impacto mayor sobre la crisis fiscal del Estado ni sobre la magnitud a la que llegó el déficit de la balanza de pagos. El mayor impacto fue el provocado por la crisis internacional y la política económica del régimen, que favoreció a los grupos bancarios (ver Tabla 4), es decir, a los conglomerados financieros y a sus empresas vinculadas locales e internacionales (Salgado, 1999).

Tabla 4. Pérdidas por la crisis 1998-1999

\begin{tabular}{|l|l|}
\hline \multicolumn{1}{|c|}{ VARIABLES } & \multicolumn{1}{|c|}{ PÉRDIDAS EN MILLONES DE DÓLARES } \\
\hline Crisis financiera internacional & 1.700 \\
Deterioro de balanza comercial & 1.538 \\
Restricciones a mercados financieros & 167 millones. Este valor por transferencias de deuda externa \\
internacionales & \\
\hline
\end{tabular}

Fuente: elaboración propia a partir de Salgado (1999).

De tal manera que el aumento de importaciones, la caída de exportaciones (pérdidas de USD 491 millones), la pérdida de ingresos por exportaciones petroleras, asociada a la caída del valor de barril (USD 632 millones), dio como resultado el deterioro de la balanza comercial, lo que originó un entorno difícil para conseguir financiamiento en moneda extranjera, por lo que, en consecuencia, se comprimió la oferta de divisas en condiciones en las que existía elevado endeudamiento privado (41\% de la deuda correspondía a ese sector) y la situación de los bancos más grandes se deterioraba (Correa, 2009).

Bajo esta situación por la que el país atravesaba, y con el peso político de los banqueros que tenían una evidente par- ticipación en el equipo de Gobierno del presidente Jamil Mahuad (1998-2000), decidieron fortalecer sus empresas ya que podían acceder a créditos (masivos) del Banco Central (Salgado, 1999).

Para la primera semana de enero del año 2000 , el tipo de cambio era de S/. 26.000 sucres por cada dólar, lo que llevó a que el presidente Jamil Mahuad impusiera el 11 de enero del 2000, un cambio de S/. 25.000 por cada dólar (ver Tabla 5). El fenómeno, conocido como "dolarización", implicaba adoptar de forma oficial el dólar como moneda de curso legal. No era una dolarización informal o de facto, en la cual una moneda extranjera circulaba simultáneamente con la moneda local, el sucre. 
Los conglomerados empresariales en el Ecuador: un análisis histórico, económico y político Giuseppe Vanoni Martínez - Carlos Rodríguez Romero

Tabla 5. Variaciones en el tipo de cambio de sucres a dólares de 1998-2000

\begin{tabular}{|l|c|}
\hline \multicolumn{1}{|c|}{ AÑO/MES } & TIPO DE CAMBIO \\
\hline 1998 & \\
\hline Agosto & S/. 5.471 \\
\hline Diciembre & S/. 6765 \\
\hline 1999 & \\
\hline Enero & S/. 7245 \\
\hline Diciembre & S/. 19.848 \\
\hline 2000 & \\
\hline $1 .{ }^{a}$ semana de enero & S/. 26.000 \\
\hline
\end{tabular}

Fuente: elaboración propia a partir de Acosta (2006) y Correa (2009).

La Tabla 6 explica las circunstancias que propiciaron una serie de inestabilidades y de decisiones que recayeron sobre el comercio de tal forma que los empresarios y entidades financieras endeudas (causantes de crisis como se puede observar), con la finalidad de poder cubrir sus obligaciones en el exterior, trataban de captar dólares para evitar las variaciones incrementales frecuentes que se daban en esa moneda.

Tabla 6. Circunstancias que llevaron a la dolarización del país

\begin{tabular}{|l|l|}
\hline \multicolumn{1}{|c|}{ SITUACIÓN } & \multicolumn{1}{c|}{ CONSECUENCIA } \\
\hline Demanda de crédito de la banca al Banco Central. & Uno de los primeros en pedirlo fue Filanbanco. \\
\hline $\begin{array}{l}\text { Crédito interno por parte del Banco Central a la } \\
\text { banca privada. }\end{array}$ & S/. 4.873.9 millones de deuda. \\
\hline $\begin{array}{l}\text { Inyecciones de liquidez no guardaban relación ni } \\
\text { con disponibilidad de divisas ni con la producción. }\end{array}$ & Devaluación e inflación. \\
\hline Ley financiera de 1994. & $\begin{array}{l}\text { Incremento de préstamos a empresas vinculadas } \\
\text { de banqueros. }\end{array}$ \\
\hline $\begin{array}{l}\text { Débil capacidad de control de los organismos } \\
\text { reguladores del sistema financiero. }\end{array}$ & Descontrol financiero. \\
\hline $\begin{array}{l}\text { Alta canalización de créditos por parte de } \\
\text { intermediarios financieros en moneda extranjera. }\end{array}$ & Incumplimiento de deudores. \\
\hline Impuesto a circulación de capitales ICC. & Disminución de depósitos a la vista. \\
\hline Retiro de dineros de los bancos. & Incremento de iliquidez de los bancos. \\
\hline $\begin{array}{l}\text { Aportaciones de bancos, más dificultad de acceso } \\
\text { a créditos internacionales. }\end{array}$ & $\begin{array}{l}\text { Tipo de cambio dólar-sucre se incrementaba con } \\
\text { rapidez. }\end{array}$ \\
\hline Venta de dólares de reserva monetaria. & Alcanzó 700 millones de dólares. \\
\hline $\begin{array}{l}\text { Abandono de sistema de bandas cambiarias a } \\
\text { flotación del cambio. }\end{array}$ & $\begin{array}{l}\text { En los dos días posteriores, el dólar se cotizaba } \\
\text { a } 18 \text { 000 sucres (devaluación de 150 \% frente a } \\
\text { cotización anterior). }\end{array}$ \\
\hline Crédito neto del Banco Central a banca privada. & Superior a USD 1 000 millones. \\
\hline Cierres de bancos. & $\begin{array}{l}\text { Estado se encargaba de su saneamiento, aunque no } \\
\text { contaba con recursos para hacerlo. }\end{array}$ \\
\hline
\end{tabular}

Fuente: elaboración propia a partir de Salgado (1999). 
Las consecuencias inmediatas, independientemente de si el proceso fue positivo o no, favorecieron directamente a los grandes deudores de la banca del país, ya que sus deudas en sucres prácticamente desaparecieron con el cambio a dólar. Y perjudicó a la clase jubilada, cuando su paga mensual por parte del Instituto Ecuatoriano de Seguridad Social (IESS) quedó en USD 4 mensuales (Herrera, 2012).

\section{CONCLUSIONES}

Si bien los momentos suscitados en el acontecer económico y político del Ecuador son difíciles de identificar por la superposición de estos en el tiempo, no podemos olvidar que para comprender la economía, como ciencia, no puede desvincularse de su historia, puesto que lo que ocurre actualmente no puede entenderse sin contemplar su pasado. Por eso, en este artículo se identificó que la formación de los actuales conglomerados tiene una base colonial, que con el transcurrir de los años se fue modificando y readecuando a los entornos, hasta alcanzar el poder e influencia que tuvieron y tienen en el ámbito nacional.

Una de las primeras actividades que iniciaron la acumulación de capitales en Ecuador, fue la relacionada con la producción y exportación cacaotera, que desde sus comienzos estaba en manos de unas pocas familias de la Costa, mientras que el capital industrial y comercial era más sólido en la Sierra ecuatoriana. Lo que nos lleva a concluir que el desarrollo capitalista históricamente fue oligopólico, tal como sucedió también con los bancos que guardaban mucha relación con los agroexportadores y terratenientes, siendo todos ellos los que, vinculados directa o indirectamente en estos sectores predominantes, en alianzas hasta cierto punto informales, manejaban los hilos económicos y políticos del país. Esto, sin olvidar que el desarrollo industrial fue tardío, débil, inestable y dependiente de las fluctuaciones económicas internacionales.

La posterior presencia del banano amplió las fronteras agrícolas, lo que hizo surgir económicamente a nuevas familias que se incorporaron al cultivo, aunque las grandes transnacionales que habían visto en Ecuador una fuente de aprovisionamiento importante para sus nuevos mercados, cada vez más crecientes, eran quienes dominaban la producción y la exportación junto al grupo bananero Noboa, que como productora nacional estaba ya establecida y se consolidaba como empresa internacional agroexportadora por medio de su flota naviera. Como se puede observar, la predominancia del modelo agroexportador primario se daba por las necesidades de los clientes externos, ávidos de la fruta, más que por las internas, aunque hay que resaltar que fue el cultivo del banano el que incorporó al país en relaciones capitalistas.

Todas las desigualdades e inequidades que en lo económico veía la sociedad generaron una serie de disturbios de tipo social, que propició que los militares 
de la época decidieran tomar el mando, para, según ellos, con un sentido más patriótico que el que habían tenido los gobiernos democráticos vinculados en mayor o menor forma a las oligarquías ecuatorianas, trabajar en pro del bienestar económico de todos. Las decisiones que se tomaron, seguramente con las mejores intenciones, no minimizaron las fortalezas de los grupos empresariales de la época, que siguieron manejando los hilos económicos y que con la ISI implementada por el régimen, ahora eran protegidos por la sustitución de las importaciones e incluso se valieron de la primera Reforma Agraria, sobre todo los hacendados de la Sierra, para vender sus tierras improductivas, con características de páramo, para comprar suelos más adecuados a los nuevos negocios en los que querían incursionar.

Bajo estas circunstancias, la ISI no alcanzó los objetivos deseados, ya que los conglomerados empresariales no ayudaron a la creación de condiciones óptimas para el modelo, y el Gobierno tampoco hizo una planificación adecuada en pro de sus propias decisiones. Sin embargo, la superposición del auge petrolero con el modelo ISI puede enmascarar lo erróneo del manejo económico por el desarrollo que el país vivió entre 1972 y 1981, siendo en este último año cuando se decide salir del modelo.
Después de las dictaduras civiles-militares y con pasos endebles de transición a la democracia, pero sólidos para los conglomerados empresariales, los cuales, como podemos observar, en los tres auges exportadores se fortalecieron y estuvieron en el manejo de los hilos económicos y políticos del país, vuelven a ser motivo de múltiples interrogantes y dudas en su accionar, cuando el Gobierno democrático del presidente Osvaldo Hurtado los salva de sus acreedores externos, al tomar, a decir de los propios beneficiados, una medida correcta, sabia y adecuada que consistió en traspasar sus deudas en dólares a sucres, decisión de naturaleza fraudulenta, que se convirtió en un mecanismo de impúdico beneficio para decenas de personas, dada la falta de control una vez aplicada la medida (Roldós, 1986) ${ }^{23}$.

El verdadero momento de consolidación de los conglomerados empresariales, ahora ya con la ley a favor de ellos, fue cuando se estableció la Ley General del Sistema Financiero en el Gobierno del presidente Sixto Durán Ballén. Si bien, y tal como se ha podido observar, estos grupos ya existían, la ley promulgada les permitió no solo diversificar sus negocios de manera relacionada o no relacionada con su core business, sino que los ayudó a salir a la luz pública con sus conglomerados ya montados y solidificados empresarialmente desde muchos años

$\overline{23}$ Vicepresidente de la República en el Gobierno de Oswaldo Hurtado. 
atrás. Y si bien, los banqueros han sido parte del quehacer diario económico y político nacional, la incorporación de la ley les dio carta blanca para realizar una serie de acciones que, paradójicamente, al margen de las leyes, pusieron al país en una de las crisis económicas más grandes sufridas y apalancadas por el Gobierno del presidente Mahuad y que culminaron con la eliminación del sucre como moneda oficial.

Como toda investigación, esta tiene sus limitaciones, y más cuando su estudio se da entre 1965-2000, ya que se considera que fue el período de mayor inestabilidad económica política, a pesar de los diferentes auges exportadores que más que beneficiar, endeudaron al país, el cual por lapsos cortos jugaba a ser un nuevo rico en los mercados internacionales.
El terreno que queda por avanzar en el estudio de los conglomerados en Ecuador es amplio, pues, si recordamos, el análisis concluye en el inicio de la dolarización y, de allí en adelante, se abre una serie de oportunidades para realizar investigaciones sobre la influencia que han tenido los conglomerados en este proceso de dolarización. Asimismo, desde el año 2007, que fue el inicio del Gobierno del presidente Rafael Correa, el número de conglomerados se ha incrementado, según información dada por el Servicio de Rentas Internas (SRI), lo que permite también estudiar qué particularidades tiene este tipo de estructuras organizacionales y cómo inciden actualmente en lo económico y político en Ecuador con un régimen que los observa detenidamente.

\section{REFERENCIAS}

Acosta, A. (2006). Breve historia económica del Ecuador (9. ${ }^{\text {a }}$ ed.). Quito: Corporación Editora Nacional.

Acosta, A. (2008). Sucretización, ¿un atraco al alimón? Oswaldo Hurtado Larrea y León Febres Cordero. Recuperado de http://www.flacsoandes.edu.ec/ sites/default/files/agora/files/1229543406.sucretizacion_2.pdf

Ayala, E. (2008). Resumen de historia del Ecuador. Quito: Corporación Editora Nacional.

Bamiatzi, V., Cavusgil, S.T., Jabbour, L. \& Sinkovics, R.R. (2014). Does Business Group Affiliation help Firms achieve Superior Performance during Industrial Downturns? An empirical Examination. International Business Review, 23(1), 195-211. 
Bisang, R. (1999). Apertura, reestructuración industrial y conglomerados económicos. Desarrollo Económico, 38, 143-176.

Bocco, A. (1987). Auge petrolero, modernización y subdesarrollo: el Ecuador de los años setenta. Quito: Corporación Editora Nacional.

Bonilla, H., (1990). La revuelta por la independencia en Hispanoamérica. Quito: FLACSO.

Cainelli, G. \& Iacobucci, D. (2011). Business Groups and the Boundaries of the Firm. Management Decision, 49(9), 1549-1573.

Carney, M., Gedajlovic, E., Heugens, P., Van Essen, M. \& Van Oosterhout, J. (2010). Business Group Affiliation, Performance, Context, and Strategy: A MetaAnalysis. Academy of Management, 54(3), 437-460.

Chiriboga, M. (1980). Jornaleros y grandes propietarios en 135 años de exportación cacaotera 1790-1925. Quito: CIESE y Consejo Provincial.

Chudnovsky, D. \& López, A. ( 1998). Las empresas multinacionales de América Latina: características, evolución y perspectivas. Boletin Informativo Technit, 297, 29-64.

Comisión Económica para América Latina y el Caribe-CEPAL-. (2013). El desarrollo económico del Ecuador (reimp.). Quito: Ministerio Coordinador de la Política Económica.

Comisión Integral de Auditoría de Crédito Público -CAIC-. (2008). Informe de cierre. Tramo sucretización. Recuperado de

http://www.auditoriadeuda.org.ec/images/stories/documentos/deuda_comercial/ Sucretizacion.pdf

Correa, R. (2009). Ecuador: de banana republic a la no república. Quito: Random House.

Dahse, F. (1979). Mapa de la extrema riqueza. Santiago de Chile: Aconcagua.

Del Villar, P., Verna, G. \& Adjerime, Y. (1999). Particularités des groupes économiques chiliens: une étude comparative nationale et internationale. Quebec: Faculté des Sciences de l'Administration, Université Laval.

De Montmorillon, B. (1986). Les groupes industriels : analyse structurelle et stratégique. París: Económica. 
El Universo (2007). La caída del Banco Continental marcó inicio de crisis financiera. El Universo.com. Recuperado de http://www.eluniverso. com/2007/11/25/0001/9/A267052F256B45B8BA8CC1868B0B237B.html

Espinosa, R. (2000). La crisis económica financiera ecuatoriana de finales de siglo y la dolarización. Recuperado de http://www.memoriacrisisbancaria.com/ www/articulos/Roque_Espinosa_Crisis_bancaria.pdf

Farías, P. (2014). Business Group Characteristics and Firm Operating Performance: Evidence from Chile. Academia Revista Latinoamericana de Administración, 27(2), 226-235.

Fierro, L. (1991). Los grupos financieros en el Ecuador. Quito: Centro de Educación Popular.

Ghemawat, P. \& Khana, T. (1998). The Nature of Diversified Business Groups: A Research Design and Two Case Studies. The Journal of Industrial Economics, 46(1), 35-61.

González F. (1970). Historia general de la República del Ecuador. Quito: Casa de la Cultura Ecuatoriana.

Granovetter, M. (1994). Business Groups and Social Organization. In N. R. Smelser \& R. Swedberg (Ed.), The Handbook of Economic Sociology (pp. 429-450). New York: Princenton University Press.

Guerrero, A. (1980). Los oligarcas del cacao. Quito: El Conejo.

Herrera, N. (2012). La crisis financiera de 1998-99 y el relevo de los grupos financieros en el Ecuador. Tesis de Maestría, Facultad Latinoamericana de Ciencias Sociales, Quito, $\quad$ Ecuador. Recuperado de http://repositorio. flacsoandes.edu.ec/bitstream/10469/5276/2/TFLACSO-2012NEHR.pdf

Herzog, J., Munir, K. \& Kattuman, P. (2013). The King and I: Monarchies and the Performance of Business Groups. Cambridge Journal of Economics, 37(1), 171-185.

Hofman, A. (1992). Ecuador: desarrollo económico en el siglo XX, un análisis cuantitativo. Cuestiones Económicas, 21, 133-166.

Hsieha, T., Yehb, R. \& Chen, Y. (2010). Business Group Characteristics and Affiliated Firm Innovation: The Case of Taiwan. Industrial Marketing Management, 39(4), 560-570. 
Hurtado, O. (1977). El poder político en el Ecuador. Quito: Ediciones de la Universidad Católica.

Khanna, T. \& Rivkin, J. (2001). Estimating the Performance Effects of Business Groups in Emerging Markets. Strategic Management Journal, 22(1), 45-74.

Khanna, T. \& Yafeh, Y. (2007). Business Groups in Emerging Markets: Paragons or Parasites? Journal of Economic Literature, 45(2), 331-372.

Kim, D., Kandemir, D. \& Kavusgil, S. T. (2004). The Role of Family Conglomerates in Emerging Markets: What Western Companies Should Know. Thunderbird International Business Review, 46(1), 13-38.

Lagos, R. (1965). La concentración del poder económico: su teoría y la realidad chilena. Recuperado de

http://www.tesis.uchile.cl/tesis/uchile/1962/lagos_r/html/index-frames.html

Larrea, C. (2005). Hacia una historia ecológica del Ecuador: propuestas para el debate. Quito: Corporación Editora Nacional.

Leff, N. (1978). Industrial Organization and Entrepreneurship in Developing Countries: The Economic Groups. Economic Development and Cultural Change, 26(4), 661-675.

Maiguashca, J. (1992) La cuestión regional en la historia ecuatoriana (1830-1972). En E. Ayala (Ed.), Nueva historia del Ecuador (pp.71-195). Quito: Corporación Editora Nacional.

Merchand, M. (2012). Estado neoliberal y acumulación por desposesión a favor del capital glocal financiero. Apuntes del Cenes, 31(54), 73-100.

Misas-Arango, G. (1975). Contribución al estudio del grado de concentración en la industria colombiana. Bogotá: Ediciones Tiempo Presente.

Moncada, J. (1995). Desigualdad y estructura productiva en el Ecuador. Quito: Corporación Editora Nacional y Colegio de Economistas de Quito.

Navarro, G. (1976). La concentración de capitales en el Ecuador. Quito: Solitierra.

Peralta, J. (1983). La esclavitud en América Latina. Barranquilla: Nuevos Caminos.

Presidencia de la República del Ecuador. (1994, 12 de mayo). Ley General de Instituciones del Sistema Financiero. Decreto Ejecutivo n. ${ }^{\circ}$ 1852, Registro Oficial 439. 
Quijano, A. (2001). Colonialidad del poder, globalización y democracia. Lima: Mimeo.

Quivy, R. \& Campenhoudt, L. V. (2005). Manual de investigación en ciencias sociales. Mexico: Limusa

Reglamento a la Ley General de Instituciones del Sistema Financiero. (1994). Registro Oficial 475 de 04-jul-1994. Decreto Ejecutivo 852.

Rodríguez-Romero, C.A. (2011). Stratégies de croissance des conglomérats colombiens. Face aux défits de la globalisation. Bogotá: Universidad Nacional.

Rodríguez-Romero, C. A. \& Duque, E. (2007). Seguimiento a la dinámica competitiva de dos grupos economicos colombianos. Revista Innovar, 17(29), 137-154.

Rodríguez-Romero, C. A. \& Duque, E. (2008). El grupo Santo Domingo: el pez chico se come al grande de generación en generación. Revista Innovar, 18(32), 127-152.

Rodríguez-Romero, C. \& Tovar, J. (2007). Fusiones y adquisiciones como estrategia de crecimiento en el sector bancario colombiano. Revista Innovar, 17(30), 77-98.

Rodríguez-Satizabal, B. (2014). Grupos económicos en Colombia (1974-1998): entre pequeña empresa familiar y gran familia de empresas. En M. Monsalve (Ed.), Grupos económicos y mediana empresa familiar en America Latina (pp. 31-58) Lima: Universidad del Pacífico.

Roldós, L. (1986). El abuso del poder. Los decretos-leyes económicos urgentes aprobados por el gobierno del ingeniero León Febres Cordero. Quito: El Conejo.

Salgado, W. (1999). Desencadenantes de la crisis económica en el Ecuador. Ecuador Debate, 48, 5-23.

Sánchez, J. \& Paredes, R. (1994). Grupos económicos y desarrollo: el caso de Chile. Recuperado de http://archivo.cepal.org/pdfs/1994/S9491197.pdf

Schuldt, J. (1980). Política económica y conflicto social. Lima: Universidad del Pacífico.

Schuldt, J. (1992). La acumulación del capital y los problemas de la macroeconomía ecuatoriana en el período de la posguerra. Quito: Ecuador Siglo XXI. Proyecto Consejo Nacional de Desarrollo/GTZ.

Silva-Colmenares, J. (1977). Los verdaderos dueños del país. oligraquias y monopolios en Colombia. Bogotá: Fondo Editorial Suramérica. 
Silva-Colmenares, J., \& Padilla, C. (2015). Transnacionalización de empresas colombianas. Conglomerados que cruzan fronteras. Bogotá: Editorial Universidad Autónoma de Colombia

Strachan, H. (1976). The rol of family and other groups in economic development: The case of Nicaragua. Nueva York: Praeger Publishers.

Tanriverdi, H. \& Venkatraman, N. (2005). Knowledge Relatedness and the Performance of Multibusiness Firms. Strategic Management Journal, 26(2), 97-119.

Uquillas, C. (2008). Modelo económico industrial en el Ecuador. Recuperado de http://www.eumed.net/cursecon/ecolat/ec/2008/au.htm

Vanoni, G. (2015). Estrategias de crecimiento de los conglomerados ecuatorianos: un estudio de cuatro grandes grupos. Ponencia presentada en III Coloquio Doctoral en Ciencias de la Administración, Dirección y Gestión (REDAC). Universidad Nacional de Colombia, Bogotá.

Vega, S. (1991). Ecuador: crisis política y Estado en los inicios de la República. Quito: Flacso y Abya-Yala.

Velasco, F (1981). Ecuador: subdesarrollo y dependencia. Quito: El Conejo.

Whitley, R. (1992). Business Systems in East Asia: Firms, Markets and Societies. London: Sage.

Wilches, G. \& Rodríguez, C.A. (2016). El proceso evolutivo de los conglomerados o grupos económicos en Colombia. Innovar, 26(60), 11-33.

Zambrano, M. (2011). Monstruos en la hacienda: el concertaje como narración de la nación. Temas, 65, 30-37. 